\title{
AVALIAÇÃO DA AUTO-CONCEPÇÃO DE SAÚDE BUCAL DE UM MUNICÍPIO CLASSIFICADO COMO DE EXTREMA POBREZA NO ESTADO DO CEARÁ
}

Vandré de Mesquita Taumaturgo*, Patricia Alexandra Martinez**, Evamiris Landim de França Vasques ***, Viviane Maria Gonçalves de Figueiredo****

\footnotetext{
Autor correspondente: Vandré Taumaturgo Mesquita - vtaumaturgo@yahoo.com.br

* Mestre em Odontologia com concentração em Clínica Odontológica pela Universidade Potiguar-RN.

** Especialista em Educação, com ênfase em Gestão e Metodologia de Ensino pela Facemed - Faculdade Educacional de Medianeira - PR.

*** Doutoranda em Odontologia pela UNICSUL-SP. Mestre em Odontologia com concentração em Clínica Odontológica pela Universidade Potiguar-RN. Especialista em Prótese Dentária pela UECE-CE.

**** Doutora em Odontologia Restauradora da UNESP-SP
}

\section{Resumo}

A saúde bucal de uma população pode ser medida por questionários realizados a fim de se obter conhecimento sobre a real situação dos usuários do SUS nos serviços odontológicos. Foram realizados quatrocentas entrevistas por meio de um questionário da população de Reriutaba-CE sobre o conhecimento em relação à importância da Saúde Bucal destes indivíduos. A pesquisa utilizou os agentes comunitários de saúde como um grupo responsável pela entrega destes. Foram distribuídos em todo o município respeitando sua quantidade amostral. Este trabalho apresentou como objetivo principal foi analisar a saúde bucal da população deste município, a fim de que novas medidas de saúde pública possam ser desenvolvidas. Como conclusão, podemos salientar que apesar desta população apresentar pouco acesso aos serviços de saúde bucal, esta apresenta uma boa concepção a respeito deste assunto de saúde e que necessitam de maior cuidado em relação à Saúde Bucal por ali ofertados.

Palavras-chave: Saúde Coletiva; Bucal; Satisfação. 


\title{
ASSESSMENT OF A POPULATION SAMPLE'S SELF ORAL HEALTH IN A COUNTRY FROM CEARÁ STATE CLASSIFIED AS EXTREMELY POOR
}

\begin{abstract}
The oral health of a population was assessed by questionnaires applied in order to gain knowledge about the real situation of SUS when it comes to dental services. We conducted 400 interviews in Reriutaba-CE on the oral health of these individuals. The research used the community health workers as the group responsible for delivering the forms. The questionaries were distributed throughout the county in regard to the sample. It has been found that in spite of this population sample's poor access to dental services, they have a fairly accurate perception regarding self oral health, indicating that new health policies may experience positive outcomes regarding oral health care. Keywords: Public Health; Oral; Satisfaction.
\end{abstract}

\section{INTRODUÇÃO}

A saúde bucal, implícita na saúde integral, está relacionada às condições socioeconômicas e culturais da população. Este tema foi inserido em uma Portaria do Ministério da Saúde, na qual a equipe de saúde Bucal passou a ser incluída na estratégia do Programa Saúde da Família (PSF). ${ }^{(1,2)}$

A saúde bucal está diretamente relacionada às condições de alimentação, moradia, trabalho, renda, meio ambiente, transporte, lazer, liberdade, acesso a serviços de saúde e informação. Nesse sentido, a luta pela saúde bucal está, fundamentalmente, ligada à luta pela melhoria dos determinantes sociais, políticos e econômicos. (1-5) $^{-1}$

A educação e a informação sobre os cuidados com a saúde bucal têm sido ressaltadas por diversos pesquisadores. O desconhecimento sobre cuidados necessários de higiene bucal representa um fator a ser considerado, uma vez que a informação, embora disponível nas grandes mídias, não chega a todas as camadas da população da mesma forma e, dificilmente, é apreendida de modo a produzir conhecimento e autonomia em relação aos cuidados com a saúde. A importância de programas odontológicos educativos, que levantem e interpretem as necessidades das populações de menor acesso aos serviços de saúde odontológicos precisa ser valorizada. ${ }^{(6,7)}$

Grandes dificuldades foram encontradas pelos municípios especialmente, aqueles que apresentam recursos financeiros limitados. O baixo poder de resolutividade dos serviços odontológicos, associado a dificuldade de inserção de profissionais nestas áreas, assim como a precariedade da estrutura e de materiais específicos foram as principais dificuldades encontradas para a Saúde Bucal. ${ }^{(8-10)}$

No intuito da necessidade de uma melhor organização das estratégias da Saúde Bucal em âmbito nacional, estas apresentam os seguintes objetivos: ampliação do acesso da população brasileira às ações de promoção e recuperação da saúde bucal, bem como, a prevenção de doenças e agravos e a melhoria dos índices epidemiológicos. ${ }^{(11)}$

$\mathrm{Na}$ reorientação do modelo de atenção, a Política de Saúde Bucal 2004, apresentou os seguintes pressupostos: a garantia de uma rede de atenção básica articulada com toda a rede de serviços 
e como parte indissociável dessa; assumir o compromisso de qualificação da atenção básica, garantindo qualidade e resolutividade, independentemente da estratégia adotada pelo município para sua organização e estabelecer política de financiamento para o desenvolvimento de ações visando à reorientação do modelo de atenção.(11)

O estado do Ceará foi um dos pioneiros em Saúde Bucal no Brasil, especialmente no município de Sobral-CE. Muitos deles apresentaram dificuldades de inserir os profissionais de Odontologia fixados na capital a virem trabalhar nos municípios de pequeno porte com baixo índice de desenvolvimento. ${ }^{(12)}$

A inserção da equipe odontológica no PSF possibilitou o avanço na prestação de serviços em saúde bucal, bem como uma maior conscientização da população de um processo saúde-doença calcado em um trabalho flexível, articulado e abrangente. ${ }^{(4)}$

Os parâmetros para orientar o processo de trabalho devem ser discutidos e pactuados entre as coordenações de saúde bucal, com o objetivo de garantir a dignidade para profissionais e usuários, respeitando assim a qualidade dos serviços prestados e observando as normas de biossegurança. ${ }^{(13)}$

Portanto, este artigo científico foi realizado mediante questionário desenvolvido em um curso de capacitação para os agentes comunitários de saúde e apresenta como objetivo principal analisar a saúde bucal da população deste município, a fim de que novas medidas de saúde pública possam ser desenvolvidas.

\section{REVISÃO DE LITERATURA}

Na década de 1970, aconteceu a Conferência Internacional sobre Cuidados Primários de Saúde, em Alma-Ata, que reafirmou: A saúde como estado de completo bem-estar físico, mental e social, e não simplesmente a ausência de doença ou enfermidade - é um direito humano fundamental, e que a consecução do mais alto nível possível de saúde é a mais importante meta social mundial, cuja realização requer a ação de muitos outros setores sociais e econômicos, além do setor saúde. ${ }^{(2)}$

Em tal contexto, o modelo de saúde vigente no Brasil era o Instituto Nacional de Previdência Social (INPS) nas décadas de 60 e 70 , que trouxe a necessidade de profundas mudanças. Era um modelo excludente, onde só quem possuía direito eram os trabalhadores formais e seus dependentes que contribuíam para a sua manutenção. ${ }^{(1-4)}$

No entanto, na prática não funcionava, filas intermináveis na entrada dos serviços de saúde, baixos salários dos funcionários que prestavam assistência e a falta de recursos básicos e tecnológicos foram características predominantes da saúde brasileira na época. ${ }^{(3-5)}$

O modelo de saúde no Brasil naquele tempo era centrado exclusivamente na técnica, ou seja, o profissional realizava, exaustivamente, seus procedimentos de saúde sem a preocupação de prevenir a incidência das patologias em um âmbito coletivo, pois não existia ainda o modelo atual de prevenção à saúde. . $^{(1,5)}$

Por conseguinte, cada vez mais aumentava o fluxo de usuários necessitando de atendimento. Além disso, houve profundas crises econômicas de corrupção por parte dos funcionários do INPS, que aposentavam pessoas sem estas nunca terem contribuído para o Instituto Nacional de Previdência Social. $(4,5)$

Diante deste caos em que se encontrava a saúde brasileira, os profissionais de saúde, estudantes e professores universitários propuseram a Reforma Sanitária na $8^{\text {a }}$ Conferência Nacional de Saúde, onde apresentaram um conceito ampliado de saúde, que era entendida como resultante das condições de vida, alimentação, lazer, acesso e posse da terra, transporte, emprego e moradia. ${ }^{(6,7)}$

Ademais, concretizaram a Universalidade, uma saúde na qual, todos tem acesso sem distinção de raça, credo e valor e que é dever do Estado fomentar este novo modelo, o Sistema Único de Saúde (SUS). ${ }^{(1-3)}$

Portanto, com a criação da Constituição Brasileira em $1988,{ }^{(3)}$ as propostas de saúde idealizadas 
durante a Reforma Sanitária, foram então contempladas, tornando um dos modelos de saúde mais avançados no mundo.

Em 1990, foi criada a Lei Orgânica da Saúde (Lei $8.080 / 90)^{(4)}$ que regulamentavam as determinações da Constituição Federal e definiam então, os princípios do Sistema Único de Saúde: Universalidade (todos e qualquer cidadão apresentam direito à saúde e dever do Estado), Equidade (tratar de forma diferenciada para os desiguais, buscando diminuir as desigualdades) e a Integralidade (prioridade na promoção e prevenção, sem prejuízo nos serviços assistenciais especializados).

Quanto aos princípios organizativos (diretrizes): Descentralização (divisão dos poderes governamentais, municipalizando as ações de serviços), Rede Regionalizada e Hierarquizada (setores da saúde divididos e integrados do nível de menor complexidade-atenção primária, passando para o de média - atenção secundária e por fim, a de maior complexidade, onde se realiza os serviços de alta complexidade e tecnologia em hospitais de grande porte ou de referência) e também a Participação da Comunidade (oficialmente representados pelos Conselhos de Saúde formados nas Conferências de Saúde). ${ }^{(1-5)}$

Apresentamos seguintes objetivos (Lei 8.080/90, Art. $\left.5^{\circ}\right):^{(4)}$ Identificar e divulgar os fatores condicionantes e determinantes da saúde; Formular políticas de saúde destinada a promover a redução de riscos à saúde com acesso universal e igualitário; Garantir assistência integral e igualitária às ações de promoção, proteção e recuperação da saúde.

No Brasil, sabemos que o direito humano à saúde é reconhecido por tratados internacionais e pela Organização das Nações Unidas (ONU). Na Declaração Universal dos Direitos Humanos de 1948, guardam os conceitos fundamentais e os direitos humanos universais (liberdade, igualdade, fraternidade, saúde, educação, trabalho, moradia, lazer, paz e dignidade). ${ }^{(4)}$

O Sistema Único de Saúde (SUS) quando implantado no final da década de oitenta por meio da Constituição Federal, apontava como primordial ação, o cuidado com a saúde por meio da alteração do processo natural de evolução da doença como também de prestar serviços à população com qualidade. ${ }^{(1)}$

Ao longo dos anos, muitos avanços foram consolidados, sendo o principal deles o Programa Saúde da Família (PSF). Idealizado em 1994, é voltado às ações básicas e possui como ideia central a coletividade. ${ }^{(8)}$

Após dez anos de sua existência surgiu uma necessidade de acompanhamento em saúde bucal. Foi então, inserida sua política em todo território nacional. Apresenta ações específicas de promoção e proteção à saúde que visam primariamente à diminuição do processo saúde-doença da população. ${ }^{(11)}$

A realização pode se efetuar pelas equipes de Saúde Bucal que são: educação em Saúde em que esta deve conscientizar a população sobre a importância da higiene oral; higiene Bucal Supervisionada em que a população apresente direito ao acesso a escovas e creme dental fluoretado; aplicações tópicas de Flúor em que se utilizam produtos fluoretados como: bochechos, gel-fluoretado e verniz-fluoretado; implantação das ações de promoção, proteção e recuperação da Saúde Bucal, desenvolvidas principalmente, pelos Técnicos em Saúde Bucal (TSB). ${ }^{(14)}$

A principal medida de prevenção coletiva da doença cárie é a fluoretação da água de abastecimento, que corresponde uma diminuição aproximada de $40 \%$ do índice de casos do tipo. Assim, percebe-se a necessidade do monitoramento dessa medida, como sendo uma das principais ações dos gestores municipais, através dos coordenadores de saúde bucal. Não obstante, os gestores de abastecimento das águas relatam altos custos para a implantação do flúor, dificultando a sua efetivação. No entanto, políticas públicas em Saúde Bucal devem ser entendidas como prioritárias por todos os gestores responsáveis por este programa em relação à saúde da população. ${ }^{(14)}$

O conceito ampliado de saúde, definido no artigo 196 da Constituição da República, ${ }^{(1)}$ deve nor- 
tear a mudança progressiva dos serviços, evoluindo de um modelo assistencial centrado na doença $e$ baseado no atendimento a quem procura para um modelo de atenção integral à saúde, incorporando ações de promoção e de proteção, ao lado daquelas propriamente ditas de recuperação que serão desenvolvidas prioritariamente.

Tais ações de saúde podem ser desenvolvidas, visando à redução de fatores de risco, que constituem ameaça à saúde das pessoas, podendo provocar-lhes incapacidades e doenças. ${ }^{(14)}$

A identificação e difusão de informações sobre os fatores de proteção são de caráter educativo. A promoção de saúde bucal está inserida num conceito amplo que transcende a dimensão meramente técnica do setor odontológico, integrando-as às demais práticas de saúde coletiva. ${ }^{(14)}$

Com a construção de políticas públicas saudáveis, o desenvolvimento de estratégias direcionadas a todas as pessoas da comunidade, devem gerar oportunidades de acesso à água tratada, inclusive a fluoretada, o uso de dentifrícios com flúor e assegurem a disponibilidade de cuidados odontológicos básicos apropriados. ${ }^{(14)}$

Neste sentido, desenvolver ações intersetoriais para ampliar a fluoretação das águas no Brasil é uma prioridade governamental, garantindo-se continuidade e teores adequados nos termos da lei 6.050 e normas complementares, com a criação e/ou desenvolvimento de sistemas de vigilância compatíveis. A organização de tais sistemas compete aos órgãos de gestão do SUS. ${ }^{(14)}$

A educação é de extrema importância na promoção à saúde bucal da população. Para tanto, devem ser trabalhadas o mais precocemente possível junto aos indivíduos. ${ }^{(12)}$

Desta maneira, a idade escolar é um período propício para o trabalho de motivação, porque além das habilidades manuais, a criança já desenvolveu uma noção das relações causa/efeito, contribuindo para o reconhecimento da importância da prevenção. ${ }^{(12)}$

Alguns autores afirmam que programas em educação voltados à saúde são importantes, pois levam os indivíduos a ter informação e atitude participativa nas ações educativas, obtendo melhorias nas suas condições de saúde, na qualidade de vida e, consequentemente, no resgate de sua cidadania. ${ }^{(12,14,15)}$

Um programa educativo deve ter como objetivo a promoção à saúde e o incentivo às mudanças, quando necessárias, de crenças, atitudes e comportamentos. ${ }^{(12)}$

No final de 1993, cresce no Brasil a discussão sobre a organização de um programa nacional de saúde geral, comunitária e de família, o que fez surgir à proposta do PSF. Este resultou das solicitações dos Secretários Municipais de Saúde, que buscavam, junto ao MS, o apoio para mudança das formas de financiamento da rede básica e a expansão do Programa de Agentes Comunitários de Saúde (PACS). ${ }^{(16)}$

Tal solicitação baseava-se na constatação de que - PACS gerava demanda por serviços de saúde e, consequentemente, necessitava incorporar outras categorias profissionais, médico e enfermeiro. Deu-se, então, uma reunião em Brasília, em 1993, cujo tema central foi "Saúde da Família". ${ }^{(16)}$

$\mathrm{Na}$ década de 1990, especificamente no final de 1993, cresce no Brasil a discussão sobre a organização de um programa nacional de saúde geral, comunitária e de família, o que fez emergir a proposta do PSF, resultando na mudança das formas de financiamento da rede básica e a expansão do PACS. ${ }^{(16)}$

Este programa foi responsável pela intervenção à saúde através da prevenção e organização da demanda, além de valorizar a integração com a comunidade. ${ }^{(16)}$

Em 1994, o Ministério da Saúde lança oficialmente o Programa de Saúde da Família (PSF), como objetivo central de reestruturação do modelo assistencial, a partir da atenção básica e priorizava as ações de proteção e promoção à saúde dos indivíduos, das famílias e das comunidades, tanto adultos como crianças, sadios ou doentes, de forma integral e contínua, com fins à melhoria do estado de saúde da população e da qualidade de vida dos brasileiros. ${ }^{(2,3)}$ 
Com o surgimento do PSF no Brasil, aconteceu no município cearense de Quixadá, em 1993, ampla discussão sobre modelos assistenciais, na qual focava um novo projeto que incorporava recursos médicos e de enfermagem e, até então, não existia como componente da equipe básica, o odontólogo. ${ }^{(2,3)}$

Assim, são estratégias operacionais do PSF, segundo MS-1999:(5) ter a família como foco de atenção, eleger o princípio de atuação pautado na vigilância à saúde, buscar o desenvolvimento do trabalho em equipe, que resgate, na prática profissional, a dimensão da atuação multidisciplinar e trabalhar a adscrição da clientela.

Do mesmo modo, a atuação do programa inclui atividades como: visitas domiciliares, realizadas principalmente pelas Agentes Comunitárias de Saúde (ACS), internação domiciliar, no intuito de humanizar e garantir maior qualidade e conforto ao paciente e sempre com acompanhamento por parte da equipe e participação em grupos comunitários, em que a equipe deve propor diagnósticos, alternativas para as resoluções dos problemas identificados como prioritários pela comunidade. ${ }^{(2,3)}$

Apenas em 06 de março de 2001, por meio de uma Portaria do Ministro da Saúde, (4) passou a incluir a equipe de Saúde Bucal, na estratégia do PSF. O plano de reorganização das ações de saúde bucal tem como objetivos: “... a ampliação do acesso da população brasileira às ações de promoção e recuperação da saúde bucal, bem como de prevenção de doenças e agravos a ela relacionados; meIhoria dos índices epidemiológicos de saúde bucal da população".

No período inicial do PSF, ${ }^{(12)}$ estudou a política de saúde bucal na atenção primária no estado do Ceará e concluiu quanto ao modelo assistencial daquela época que os produtos alcançados não foram os que se almejavam. Segundo ela, ocorria uma mistura de dois modelos de atenção em saúde bucal (flexneriano e integral).

Com isso, não se alcançou o objetivo da saúde bucal coletiva, verticalmente integrada nos níveis de atenção e as demais política de saúde. Na prá- tica, ela ainda afirma ser um modelo centrado no curativo, tradicional, mutilador, ofertado a grupos de risco ou prioritários, sem qualquer justificativa epidemiológica e de excluir o restante da população a qual fica reservada e restrita às urgências e às emergências odontológicas. ${ }^{(12)}$

Houve $^{(8)}$ uma melhoria na saúde bucal da população, comprovada nos trabalhados epidemiológicos desenvolvidos. Para comprovar a importância da reestruturação do PSF, foram feitas pesquisas para mensurar a cárie, como sendo a principal enfermidade oral.

Através da epidemiologia, existe um índice que quantifica dentes cariados $(C)$, perdidos $(P)$ e obturados $(\mathrm{O})$ - CPOD, tomando como idade de referência internacional, adotada pela Organização Mundial de Saúde, os 12 anos. Em 2006, apontava a razão de 3,1 no Brasil e 3,01 no estado do Ceará, ambos dentro do padrão aceitável segundo o mesmo organismo internacional. ${ }^{(17)}$

Contudo, alguns autores constatam a continuidade de doenças orais na população brasileira, persistindo ainda a necessidade de ações que deveriam ser realizadas e não as foram até então, em alguns territórios dentre eles, o estado do Ceará.(4)

Segundo Pinto, (7) houve um aumento significativo na cobertura populacional pelas equipes de PSF no Ceará. No entanto, no período de 2001 a 2007, não foram observadas mudanças significativas nos indicadores de saúde bucal. A pesquisa demonstra que com a implantação da saúde bucal no PSF, ainda não obteve êxitos significativos.

A qualidade na rede ensino-serviço também deve ser vislumbrada na pesquisa, pois é através desta que podemos construir um elo eficaz, visando à melhoria da qualidade de vida da sociedade através da integralidade das ações do SUS. ${ }^{(13,18,19)}$

Logo a qualidade, tradicionalmente falando, relacionava-se com o produto final, seja ele um bem ou serviço. Atualmente, o gerenciamento da qualidade é uma nova doutrina em que os pensadores ampliam esta visão relacionando-a, principalmente, com o processo através do qual os produtos são materializados. ${ }^{(13,18,19)}$ 
Refere-se a três dimensões para a qualidade dos serviços de saúde: o desempenho técnico, ou seja, aplicação do conhecimento e da tecnologia médica, de modo a maximizar os benefícios e reduzir os riscos; as relações interpessoais, isto é, o relacionamento com o paciente; e as amenidades pretendidas de conforto e estética nas instalações e nos equipamentos. ${ }^{(17)}$

A satisfação poderá estar presente ou não, em qualquer uma das dimensões supracitadas, bastando que as expectativas dos usuários em questão tenham sido percebidas e posteriormente resolvidas. ${ }^{(13)}$

Em ato contínuo, ele definiu o conceito de qualidade e enumerou os sete pilares: eficácia (o meIhor que podemos fazer, em condições mais favoráveis possíveis); efetividade (alcançarmos o melhor, porém as condições não foram ideais); eficiência (efeito máximo, no menor custo); aceitabilidade (relaciona-se com a expectativa do usuário: conformidade dos serviços com as aspirações e expectativas dos pacientes e familiares); otimização (criação de condições mais favoráveis para a resolução de algum problema); legitimidade (aceitação e aprovação dos serviços de saúde pelos usuários) e equidade (esforço para diminuir as desigualdades)..$^{(19,18)}$

Em $1991^{(19)}$ definiu qualidade acrescentando as características acessibilidade, adequação e qualidade técnico-científica. Segundo, ${ }^{(15)}$ o Programa de Qualidade de Serviço Público é a principal ferramenta e apresenta como objetivo tornar a administração pública transparente, participativa e preparada para responder às demandas sociais, tornando os cidadãos mais exigentes e elevando o padrão dos serviços.

Este ${ }^{(15)}$ afirma que a saúde é vista hoje, por alguns autores, como um setor estratégico do Governo e da sociedade, devido à sua importância econômica e social, motivo pelo qual é considerada como um elemento fundamental na composição da qualidade de vida.

\section{METODOLOGIA}

O tipo de estudo é quantitativo e amostral sendo respeitado por tamanho da população do município da macrorregião de Sobral. O município é classificado com município de extrema pobreza e foi escolhido pela experiência profissional do referido autor em exercer suas funções de gestão nesta cidade cearense.

A pesquisa foi realizada através de um questionário sobre o conhecimento da população em Saúde Bucal. Foram realizados quatrocentos questionários entregues aos agentes comunitários de saúde do município e de forma aleatória, entregue à população respeitando a territorialização do município assim como a sua distribuição populacional.

Esta pesquisa foi realizada através de um curso de capacitação sobre a saúde bucal enfatizando as questões das patologias existentes na Odontologia, assim como, as práticas preventivas de abordagens dos agentes comunitários de saúde em relação as suas atividades dentro de seu território municipal.

\section{RESULTADOS}

Os referidos resultados foram calculados através do programa Excel (Microsoft) e os cálculos foram realizados no sistema de porcentagem simples para cada frequência das respostas de cada indivíduo.

Em relação a idade média das pessoas que responderam o questionário foi até 20 anos de idade, com 39\% (156) das pessoas entrevistadas, com 30 anos com $30 \%$ (120) dos sujeitos da pesquisa, $21 \%$ (84) até 50 anos, após 50 anos com 10\%(40) dos entrevistados e não havendo nenhum sujeito com idade de até 10 anos.

Já na questão em que se questiona qual deve ser a frequência de escovação, os usuários responderam que $43 \%$ (172) devem escovar os dentes três vezes ao dia, $12 \%$ (48) dos entrevistados responderam que deve escovar uma única vez ao dia, $16 \%$ (64) que deve escovar duas vezes e $17 \%$ (68) os 
sujeitos responderam que devem escovar quatro vezes ao dia e enquanto, apenas 19\% (76) sabiam que a escovação depende do número de vezes em que ocorre a alimentação.

$\mathrm{Na}$ questão onde foi indagado a hora mais importante de escovar os dentes, 34\% (136) responderam que pela manhã, enquanto $47 \%$ (188) responderam que pela noite, $10 \%(40)$ responderam pelo meio-dia, 6\% (24) pela tarde e apenas 3\% (12) pela madrugada.

No quesito do uso do fio dental, 29\% (116) dos usuários responderam que devem passar ás vezes em que se alimentam, outros $20 \%$ (80) preencheram em dizer que apenas deve passar o fio dental duas vezes ao dia, 35\% (140) que deve passar apenas uma vez ao dia, cerca dos $11 \%$ (44) devem passar três vezes apenas $5 \%$ (20) quatro vez ao dia.

Em relação à troca de escovas dentais, $44 \%$ (176) dos entrevistados responderam em trocar a cada 90 dias (3 meses), já $25 \%$ (100) em 60 dias ou (2 meses), $11 \%$ (44) que deve ser trocada todo mês, $12 \%$ (48) dos sujeitos da pesquisa deve trocar em 4 meses e apenas $8 \%$ (32) dos entrevistados devem trocar em 5 meses de uso da escova.

Nas visitas ao dentista, 35\% (140) dos usuários responderam que devem ir ao dentista três vezes por ano, enquanto $27 \%$ (43) preencheram o questionário para duas vezes ao ano, 20\% (80) responderam que devem ir apenas uma vez por ano ao dentista, $12 \%$ (48) quatro vezes e apenas $6 \%$ (24) que deve ir cinco vezes ao dentista por dia.

No conhecimento sobre as patologias buxais 83\% (332) responderam saber o que é a doença cárie, outras $10 \%$ (40) não sabem o que é esta patologia, $2 \%$ (8) não ouviram nem falar o que é carie dental e $5 \%$ (20) já ouviram falar o que é cárie dentaria.

Esta imensa maioria sobre a patologia da doença cárie, não foi a mesma quando foi questionado sobre a doença periodontal, apenas $31 \%$ (124) responderam saber o que é esta doença oral, outras $40 \%$ (16) não sabem o que é a doença periodontal, outras $20 \%$ (8) nunca ouviram falar e apenas $9 \%$ (36) já ouviram falar sobre a doença periodontal.
Cerca de 79\%, (316) responderam dizem que sabe para qual a finalidade do flúor, apenas 10\% (40) não sabem sobre responder sobre a existência do flúor, outras 3\% (12) nunca ouviram falar e $8 \%$ (32) já ouviram sobre a finalidade do flúor.

Os sujeitos da pesquisa cerca $34 \%$ (136) dos usuários deram nota 07 (sete) sobre a saúde bucal de sua família, outros $26 \%$ (104) responderam nota 09 (nove), $20 \%$ (80) deram nota cinco, $12 \%$ (48) ofereceram nota máxima a saúde bucal de sua família e apenas $8 \%$ (12) deram nota três.

\section{DISCUSSÃO}

Os moradores deste município cearense após o uso do questionário apresentaram um conhecimento genérico da Odontologia. Este pode ser adquirido de várias formas de comunicação como televisão, internet, rádio, jornal e outros. Além destes, foi adquirido esta educação em saúde, por profissionais que realizaram campanhas educativas em escolas, igrejas e clubes recreativos incentivando a população sobre a importância da Saúde Bucal. Estas campanhas educativas estão previstas como atividades inerentes especificas da Saúde Bucal. ${ }^{(4,5)}$

Sobre as patologia bucais, a doença periodontal, classificada como a segunda doença de maior incidência na população brasileira, não é de conhecimento destes usuários. ${ }^{(12)}$ No entanto, muitos conhecem como nomes populares como "piorréia". Deve-se principalmente, ser uma doença crônica em que normalmente, consegue-se ser controlada e tratada ainda, em ações básicas. Então, a população normalmente, não ocorre a ligação da chamada "limpeza" como o controle desta patologia descrita na literatura. ${ }^{(6,7)}$

Já a doença cárie é de conhecimento de todos, bem como os métodos mecânicos de limpeza, estes sendo de conhecimento da grande maioria, inclusive quando se deve trocar. Assim como, a frequência das escovações e fio dental. Já que é considerada a patologia de maior incidência e que podem trazer danos irreversíveis de mutilação e sequelas. ${ }^{(6,7)}$ Ela se apresenta de uma forma clara é 
que a população necessita de cirurgiões-dentistas regularmente oferecendo seus serviços e que ocorra a efetivação da Política de Saúde Bucal. $(4,5)$

O município é classificado como extrema pobreza, embora vem melhorando suas condições de vida e qualidade por deter dos programas nacionais sociais que fazem com que a população detenha um maior poder aquisitivo sócio-cultural. ${ }^{(1,2)}$

No entanto, devido a precariedade dos serviços principalmente, os odontológicos a população mostra sinais claros que ainda não possuem uma situação desejável em relação a Saúde Bucal, visto que consideram como boa a muito boa as relações de qualidade bucal. Até que ponto este questionário apresenta a real situação da Saúde Bucal destes indivíduos é difícil de diagnosticar, mas mostra claramente a desconcertante situação.

\section{CONCLUSÃO}

A população deste município apresenta uma boa concepção dos conhecimentos referentes à importância da Saúde Bucal em seus hábitos diários. No entanto, este conhecimento a respeito do assunto ratifica a real situação destes usuários, visto que, são moradores de um território de extrema pobreza em que os programas sociais se fazem necessário.

Infelizmente, a Saúde Bucal ainda se encontra por muitos ainda elitista em que consultórios odontológicos na região são utilizados apenas pela elite local. No entanto, os índices de cárie e outras patologias vêm decrescendo satisfatoriamente. E este município não é diferente, com as atividades dos profissionais de saúde bucal do município, com certeza teremos um aspecto totalmente após mais alguns anos, respeitando os princípios e diretrizes do SUS.

\section{REFERÊNCIAS}

1. Brasil. Constituição 1988. Constituição da República Federativa do Brasil. Brasília (DF): Senado; 1988.
2. Ministério da Saúde (BR). Lei n ${ }^{\circ} 8.080$, de 19 de setembro de 1990. Dispõe sobre as condições para a promoção, proteção e recuperação da saúde, a organização e o funcionamento dos serviços correspondentes e dá outras providências. Brasília, DF; 1990.

3. Ministério da Saúde (BR). Manual para organização da atenção básica de saúde. Brasília, DF; 1999.

4. Ministério da Saúde (BR). Brasil sorridente: a saúde bucal levada a sério. Brasília, DF; 2004.

5. Ministério da Saúde (BR). Secretaria Nacional de Programas Especiais de Saúde. Divisão Nacional de Saúde Bucal. Fundação de Serviços de Saúde Pública. Brasília, DF; 1988.

6. Pinto VG. A questão epidemiológica e a capacidade de resposta dos serviços de saúde bucal no Brasil [tese]. São Paulo: Universidade de São Paulo; 1992.

7. Pinto VG. Saúde bucal coletiva. $4^{\mathrm{a}}$ ed. São Paulo: Santos; 2000.

8. Política Nacional de Saúde Bucal. Divisão Nacional de Saúde Bucal. Disponível em http:// drt2001.saude.gov.br/sps/areastecnicas/bucal/ publicacoes/. Acesso em 24 de outubro de 2002. Brasil 1993.

9. Vuori H. A qualidade da saúde. Divulgação em Saúde para Debate. 1991;1:17-25.

10. Almeida ES, Chioro A, Zioni F. Políticas públicas e organização do sistema de saúde: antecedentes, reforma sanitária e o SUS. In: Almeida ES, Westphal MF Coordenadores. Gestão de serviços de saúde: descentralização/ municipalização. São Paulo: EDUSP; 2001.

11. Garcia PPNS, Corona SAM, Valsecki Júnior A. A educação e motivação: segunda avaliação da efetividade de métodos educativos-preventivos relativos à cárie dental e à doença periodontal. Rev Odontol Unesp. 1998; 27(2):4O5-415.

12. Pequeno LL. A Política de Saúde Bucal na Atenção Primária do Estado do Ceará: 19942003 [dissertação]. Fortaleza: UECE; 2005.

13. Donabedian A. Explorations in Quality Assessment and Monitoring Vol. 1. The Definition of Quality and Approaches to Its Assessment. Ann Arbor, MI: Health Administration Press; 1980. 
14. Gomes AS, Gianlup EM, Abreu CSB. A importância da conscientização e da prática preventiva em odontologia. Rev Odonto Ciênc. 1993;8(16):115-125.

15. Ministério da Educação (BR). Parâmetros curriculares nacionais: meio ambiente, saúde. Brasília: Secretaria de Educação Fundamental; 1999. v. 9.

16. Declaração de Alma-Ata. Conferência Internacional sobre cuidados primários de saúde; 6-12 de setembro 1978; Alma-Ata; USSR.
17. Albuquerque VS, Gomes $\mathrm{AP}$, Rezende CHA, Sampaio MX, Dias OV, Lugarinho RM. A integração ensino-serviço no contexto dos processos de mudança na formação superior dos profissionais da saúde. Rev Bras Educ Méd. 2008;32(3): 356-62.

18. Donabedian A. The seven pillars of quality. Arch Pathol Lab Med. 1990;114(11): 1115-8. 1990.

19. Donabedian $A$. The quality of care: how can it be assessed. J Am Med Assoc. 1988;26O(1):743-748. 